\title{
Property Evaluation of Vapor-Deposited TiN Film by the Analysis of Elastic Waves* (1st Report, Nondestructive Evaluation of Elastic Properties by Laser Surface Acoustic Waves)
}

\author{
Hideo $\mathrm{CHO}^{* *}$, Singo OGAWA***, \\ Kazushi YAMANAKA**** and Mikio TAKEMOTO**
}

\begin{abstract}
The elastic properties of TiN films deposited on stainless steel SUS317J2 by three physical vapor deposition methods were estimated from the velocity dispersion of laser surface acoustic waves (SAWs) in the frequency range of 30 to $60 \mathrm{MHz}$. The velocity dispersion of Rayleigh waves was obtained by the scanning interference fringes (SIF) system and was used to estimate the elastic stiffness of the films. Depending on the deposition method, Young's moduli of TiN films were found to increase in the order of activation reaction method (ARE) $\rightarrow$ hollow cathode discharge $(\mathrm{HCD}) \rightarrow$ arc ion discharge (AID) method. The attenuation of SAWs was the highest for AID film due to the poor quality of the film.
\end{abstract}

Key Words: Nondestructive Evaluation, Titanium Nitride, Elastic Properties, Laser Surface Acoustic Waves, Scanning Interference Fringes, Physical Vapor Deposition

\section{Introduction}

Titanium nitride (TiN) and titanium nitridecarbide $\mathrm{Ti}(\mathrm{C}, \mathrm{N})$ are widely used as hard-facing films of machining tool and wear components due to their excellent wear resistance ${ }^{(1)}$. We have in the past ${ }^{(2),(3)}$ examined the feasibility of using $\operatorname{TiN}$ and $\operatorname{Ti}(\mathrm{C}, \mathrm{N})$ as hard-facing coating of let-down valve components in a coal-liquefaction process which suffers from serious slurry erosion. Stainless steel SUS317J2 $\left(25 \mathrm{Cr}-13 \mathrm{Ni}^{-}\right.$ $0.8 \mathrm{Mo}-0.05 \mathrm{C}-\mathrm{Fe}$ ) with Vickers hardness of 320 was used as the substrate metal for the let-down valve,

* Received 24th September, 1997. Japanese original: Trans. Jpn. Soc. Mech. Eng., Vol.63, No.609, A (1997), p. 1050-1056 (Received 22nd July, 1996)

** Faculty of Science and Engineering, Aoyama-Gakuin University, 6-16-1 Chitosedai, Setagaya-ku, Tokyo 157-8572, Japan

*** Graduate School, Aoyama-Gakuin University, 6-161 Chitosedai, Setagaya-ku, Tokyo 157-8572, Japan (Present: Electric Power Development Co., Ltd.)

**** Mechanical Engineering Laboratory 1-2 Namiki, Tsukuba, Ibaraki 305-0044, Japan (Present: Department of Materials Processing, Tohoku University, Aoba, Sendai 980-0845, Japan) because of its superior corrosion resistance and machinability. However, its hardness is lower than that of superhard alloys such as Co-WC, which is often used as machining tool. Wear resistance of hardfacing coatings depends significantly on the characteristics of both the film and substrate metal because the film tends to exfoliate from the deformed soft substrate metal.

Since the physical and mechanical properties of TiN and $\mathrm{Ti}(\mathrm{C}, \mathrm{N})$ films deposited by PVD and CVD can be controlled by selecting substrate and vapor deposition conditions, the properties of these films should be evaluated in a nondestructive way. However, to our knowledge, there is no widely accepted method for evaluating the properties of films with thickness of 4-5 micrometers. Accurate evaluation of the elastic stiffness and Poisson's ratio of thin films is important particularly in the measurement of residual stress by the X-ray method and also in the calculation of the adhesion strength of the film. The ultrasonic spectroscopic method has recently enabled the measurement of elastic stiffness of thin films; however, it requires a liquid couplant for transmitting and receiving ultrasonics ${ }^{(4),(5)}$. Since the ultrasonic waves are 
measured for specimen set in water, wave attenuation in the film, which provides information on pinholes (or pores), can hardly be measured.

On the other hand, surface acoustic wave (SAW) has often been used for estimating the elastic properties of thin films because it reveals the characteristic dispersion of velocity and attenuation depending on both elastic properties and thickness of the film ${ }^{(6),(7)}$. In order to measure such properties of thin films, a wide frequency band SAW system is required.

We have developed a noble laser SAW system with wide frequency band up to $110 \mathrm{MHz}$. With this, we measured the velocity and attenuation dispersion of $\mathrm{TiN}$ and $\mathrm{Ti}(\mathrm{C}, \mathrm{N})$ films deposited by three PVD methods. Among the SAWs, the velocity dispersion of the Rayleigh wave can be accurately computed from the given elastic properties, density and thickness of the film. The properties were estimated by the inverse processing of the measured velocity dispersion of the Rayleigh wave.

In general, the physical and mechanical properties of the film are influenced by the quality of the film, which is, in turn, affected by grain size, preferential orientation, porosity, impurity and residual stress. The SAW system with limited frequency band cannot measure all these microproperties. Therefore, in this paper, we mainly discuss the effect of porosity (or cavity) and inclusion in the films on the dispersion of velocity and attenuation. We also discuss the correlation between the properties estimated from SAW and the fracture strength of films estimated by the source simulation of acoustic emission (AE). In the present paper, we introduce a newly developed wide-band laser SAW system, the elastic properties of TiN and $\mathrm{Ti}(\mathrm{C}, \mathrm{N})$ films estimated from the velocity dispersion of the Rayleigh wave, and porosity and inclusion in the films estimated from the attenuation dispersion.

\section{Specimen}

We used $\mathrm{TiN}$ and $\mathrm{Ti}(\mathrm{C}, \mathrm{N})$ films deposited on SUS317J2 steel by activation reaction evaporation (ARE), arc ion discharge (AID) and hollow cathode discharge (HCD) methods. The specimens are, as shown in Table 1, expressed as ARE-N, AID-N, HCD$\mathrm{N}$ and ARE-CN. The symbols $-\mathrm{N}$ and $-\mathrm{CN}$ imply TiN and $\operatorname{Ti}(\mathrm{C}, \mathrm{N})$, respectively. However, $\mathrm{Ti}(\mathrm{C}, \mathrm{N})$ film was deposited only by the ARE method. The films were deposited at $350^{\circ} \mathrm{C}$ by a professional company. The films were deposited by the following procedure to improve their adhesion strength: 1) deposition of metallic titanium film of $0.1 \mu \mathrm{m}$ thickness by ion bombardment ; 2) deposition of $\mathrm{TiN}$ or $\mathrm{Ti}(\mathrm{C}, \mathrm{N})$ of 2 $\mu \mathrm{m}$ thickness by one of the above three methods ; 3 ) deposition of metallic titanium of $0.1 \mu \mathrm{m}$ thickness by
Table 1 Four kinds of TiN, Ti (C, N) coatings deposited on SUS317J2 steel

\begin{tabular}{|c|c||c|c|c|c|}
\hline No. & $\begin{array}{c}\text { Sample } \\
\text { name }\end{array}$ & $\begin{array}{c}\text { Deposition } \\
\text { method }\end{array}$ & $\begin{array}{c}\text { Deposited } \\
\text { film }\end{array}$ & $\begin{array}{c}\text { Vickers } \\
\text { hardness Hv }\end{array}$ & $\begin{array}{c}\text { Porosity } \\
\%\end{array}$ \\
\hline \hline 1 & ARE-CN & $\begin{array}{c}\text { Activated } \\
\text { Reactive } \\
\text { Evaporation }\end{array}$ & $\mathrm{Ti}(\mathrm{C}, \mathrm{N})$ & 2600 & 6.65 \\
\hline 2 & AID-N & $\begin{array}{c}\text { Arc Ion } \\
\text { Discharge }\end{array}$ & $\mathrm{TiN}$ & 2150 & 31.2 \\
\hline 3 & HCD-N & $\begin{array}{c}\text { Hollow } \\
\text { Cathode } \\
\text { Discharge }\end{array}$ & $\mathrm{TiN}$ & 1750 & 7.14 \\
\hline 4 & ARE-N & $\begin{array}{c}\text { Activated } \\
\text { Rective } \\
\text { Evaporation }\end{array}$ & $\mathrm{TiN}$ & 1100 & 5.30 \\
\hline
\end{tabular}
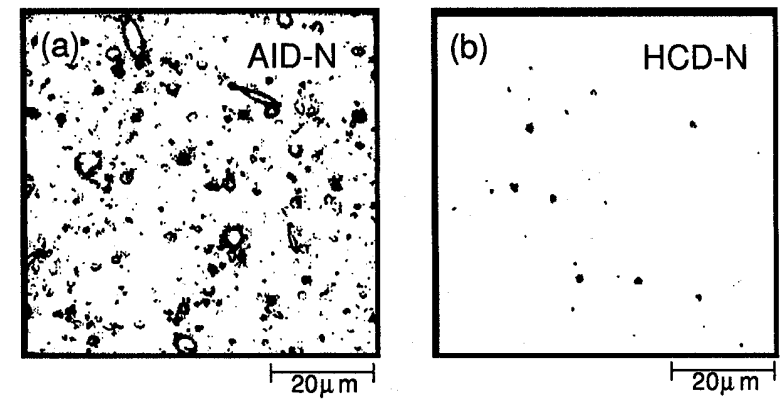

Fig. 1 Surface topograph of AID-N and HCD-N films by laser microscopy

ion bombardment; and 4) deposition of $2-\mu \mathrm{m}$-thick $\mathrm{TiC}$ or $\mathrm{Ti}(\mathrm{C}, \mathrm{N})$. Thus each film consists of the following four layers: substrate metal/metallic $\mathrm{Ti} /$ bottom TiN/metallicTi/top TiN.

The craters, pores and splashed particles in the film were measured using a laser microscope. Since the craters and splashed particles could not be separately measured using the laser microscope, these are treated as the defects in this research because the craters are often caused by fallingoff of the splashed particles and vacancies exist along the splashed particles $^{(8)}$. In Fig. 1, typical laser microscopic photographs of AID-N and HCD-N films are shown. The AID-N film shows large defects in particular, in-plane porosity reaches $31.2 \%$. In contrast, the defects in the $\mathrm{HCD}$ film are generally small and the porosity is estimated to be $5.30 \%$. The higher porosity of the AID-N film is assumed to be due to the heavy bombardment by titanium ions.

Figure 2 shows the relationship between Vickers hardness (Hv) and applied load. Accurate hardness measurement of TiN film was extremely difficult due to the presence of the metallic titanium layer. For instance, the diagonal distance of indentation at 0.049 $\mathrm{N}$ is about $2 \mu \mathrm{m}$, which is exactly the thickness of the top TiN layer; however, it is influenced significantly by reading error. At a larger load, the difference in hardness between the films becomes unclear due to the effect of the substrate metal. We used the hardness 


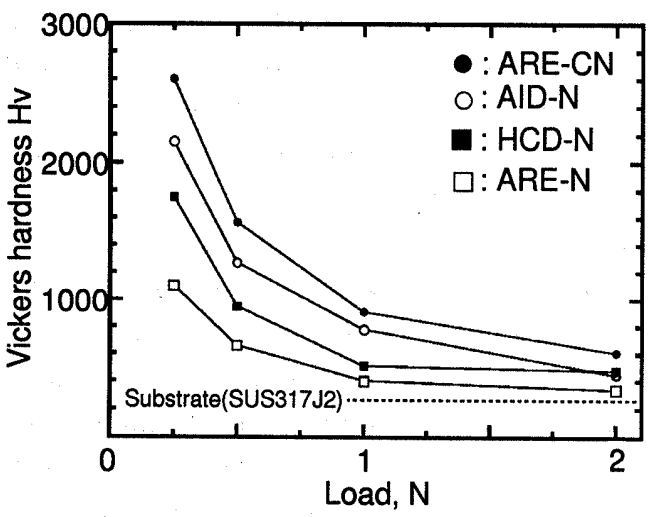

Fig. 2 Dependence of Vickers hardness on applied load

determined by a load of $0.245 \mathrm{~N}$, in which the diagonal distance is between 3.5 and $4 \mu \mathrm{m}$. The hardness of the AID film scatters significantly due to a high degree of porosity, but is shown in the figure as average hardness of 15 measurements. The hardness of the AID film is the highest among the films studied in spite of its high porosity. This is assumed to be due to the compressive residual stress induced by the shot-peening effect of ion bombardment. The hardness of the AID film was reported to be measured as higher value due to the elastic recovery of indentation after unloading ${ }^{(3)}$. The same result was reported, by Mizuguchi et $\mathrm{al}^{(9)}$, for the TiN film deposited on stainless steel by the AID method.

Although the hardness as well as the velocity of the Rayleigh wave is affected by residual stresses and intrinsic stresses ${ }^{(10)}$ induced by particle inbedding, it is at present almost impossible to measure true film properties, that are not influenced by residual stress.

\section{Laser SAW System and Velocity Dispersion}

In order to measure the velocity dispersion over a wide frequency band, we developed a new laser SAW system (scanning interference fringe at phase velocity, abbreviated as the SIF system), in which two laser beams with different wave numbers were scanned at the velocity of the Rayleigh wave ${ }^{(11)}$. The system is illustrated in Fig. 3. Two laser beams of $\mathrm{Q}^{-}$switched $\mathrm{Nd}-\mathrm{YAG}$ with frequencies of $\omega_{1} / 2 \pi$ and $\omega_{2} / 2 \pi$ were focused on the film surface at angles $\theta_{1}$ and $\theta_{2}$ to produce scanning interference fringes. The dispersion of the phase velocity and the attenuation of the Rayleigh wave were measured by changing the frequency difference $\omega_{a} / 2 \pi=\left(\omega_{1} / 2 \pi-\omega_{2} / 2 \pi\right)$ using a frequency-variable Bragg cell $(30-110 \mathrm{MHz})$. The positions of both the mirrors and the Bragg cells were precisely controlled using computer-controlled stages. The transmitted Rayleigh waves were measured by an optical knife edge system with an avalanche photodiode detector for which an argon ion laser,

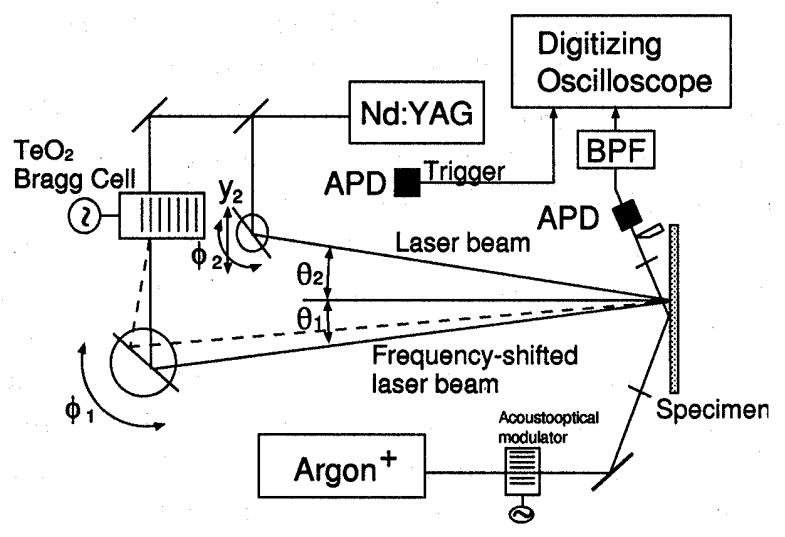

Fig. 3 Schematic illustration of scanning interference fringes

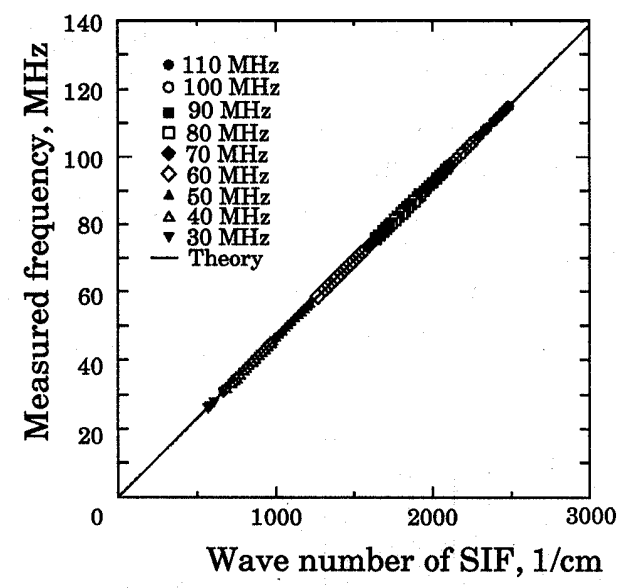

Fig. 4. Phase velocity dispersion of pure alminum measured by the SIF system

chopped by an optical modulator, was used as the probe laser.

The phase velocity of the SAW generated by this method is given by ${ }^{(12)}$

$$
V_{\text {saw }}=\omega / k_{f}
$$

where $\omega$ is the angular frequency determined by the spectral analysis of the monitored SAW. $k_{f}$ denotes the wave number of the interference fringe and is given by

$$
k_{f}=2 k \sin \left[\left(\theta_{1}+\theta_{2}\right) / 2\right]
$$

Since the phase velocity is significantly affected by the accuracy of small angle of incidence, $\theta_{1}$ and $\theta_{2}$, the angles are measured using a pure aluminum plate as the reference material. Figure 4 shows the phase velocity dispersion of pure aluminum in the frequency range from 30 to $110 \mathrm{MHz}$. The error in the phase velocity is estimated to be less than $1 \%$. The dispersion of the SAW can be determined simultaneously with the phase velocity by changing the SAW propagation distance.

\section{Results and Discussion}

We measured the phase velocity of the Rayleigh 
wave in the frequency range from 30 to $60 \mathrm{MHz}$. In Fig. 5 are illustrated the typical detected wave ( a ) and its power spectrum at $50 \mathrm{MHz}$ ( $b$ ) for the AID-N film. The detected wave is the average of 20 measurements and shows a $\mathrm{S} / \mathrm{N}$ ratio higher than $20 \mathrm{~dB}$. The velocity dispersion was determined from the frequency of the maximum peak of $(b)$, and is shown in Fig. 6.

The phase velocity increases with frequency because the Rayleigh wave velocity of TiN film is higher than that of the substrate metal. The velocity dispersion changes significantly depending on the deposition method. For instance, the velocity at 50 $\mathrm{MHz}$ is highest for the AID-N film, and is almost 120 $\mathrm{m} / \mathrm{s}$ higher than that of the ARE-N film. Data scatter of the ARE-N film, which has the highest porosity, is large compared to that of other films. In contrast, the ARE-CN film showed the highest velocity and its data scatter is the smallest.

We estimate the elastic properties of TiN films from these velocity dispersions using the matrix transfer method of Adler et $\mathrm{al}^{(13)}$. The properties of film are determined such that the computed dispersion for
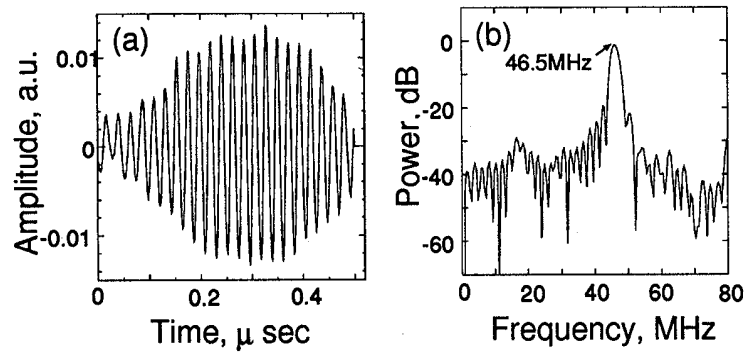

Fig. 5 Example of monitored SAW (a) and its power spectrum (b)

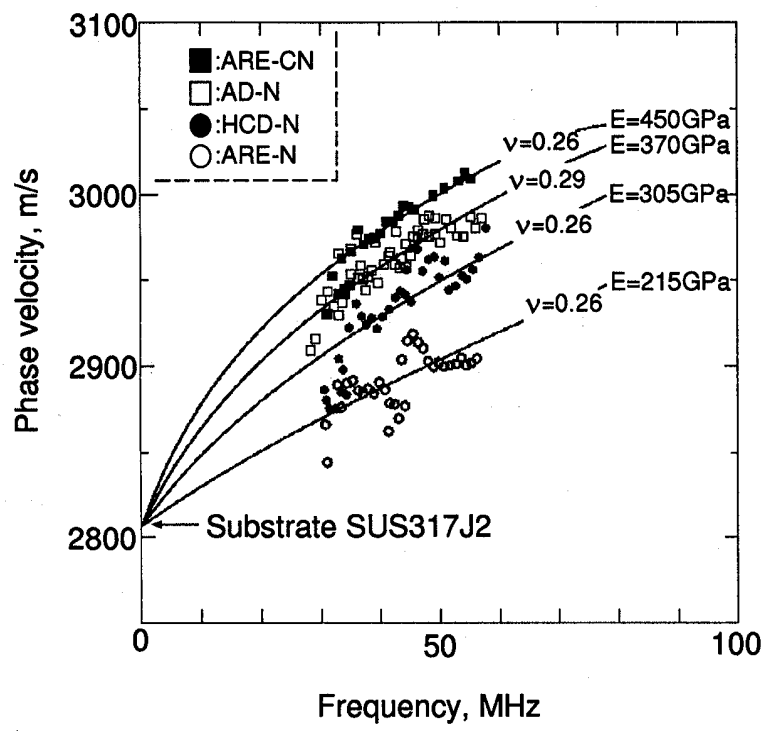

Fig. 6 Phase velocity dispersion of the Rayleigh wave for four kinds of $\mathrm{TiN}$ andTi $(\mathrm{C}, \mathrm{N})$ films. a 5 -layer structure of $\mathrm{SUS} / 0.1 \mu \mathrm{m} \mathrm{Ti} / 2 \mu \mathrm{mTiN} / 0.1$ $\mu \mathrm{m} \mathrm{Ti} / 2 \mu \mathrm{m}$ TiN agrees with the experimental dispersion. Computation was performed under three assumptions : 1) TiN is an isotropic elastic material ; 2) both elastic properties and density change stepwise at each interface ; 3) each layer is mechanically continuous, or the stresses and strains across the interface are continuous. Assumption 3) is valid because the TiN film showed excellent adhesion under compressive loading. Assumption 1) might be incorrect because the TiN film is considered to grow epitaxially and usually shows preferential orientation. However, it is almost impossible to measure the orientation dependence of the phase velocity dispersion by the laser SAW system due to the limited spatial resolution of the system. We assume here that $\mathrm{TiN}$ is an isotropic elastic material. Under these assumptions, we have to determine Young's modulus $E$, Poisson's ratio $\nu$ and density $\rho$ of TiN and titanium metal, given the thickness of each layer. However, the estimation of three unknown properties is likely to lead us to overestimation. Thus we used Poisson's ratio estimated by the strain gauge method. Shown in the Fig. 6 are the experimental Poisson's ratio (0.26-0.29), which seems to be slightly larger than that reported for bulk TiN (0.236) ${ }^{(14)}$. Poisson's ratio of the SiC film deposited by CVD is reported to be $0.35-0.36^{(15)}$, and is larger than that of bulk $\mathrm{SiC}$. We also examined the effect of Poisson's ratio on the phase velocity dispersion by computer simulation, and found that the change in Poisson's ratio from 0.2 to 0.29 increased the phase velocity by only $5 \mathrm{~m} / \mathrm{s}$. This velocity change is within the experimental error of phase velocities in Fig. 6. Next we computed the phase velocity dispersion of the TiN film using Poisson's ratio in the figure and a density of $5210 \mathrm{~kg} / \mathrm{m}^{3(16)}$. Young's modulus, Poisson's ratio and density are taken to be $196 \mathrm{GPa}$, 0.27 and $8000 \mathrm{~kg} / \mathrm{m}^{3}$ for SUS317J2 steel, and $115 \mathrm{MPa}$, 0.37 and $4540 \mathrm{~kg} / \mathrm{m}^{3}$ for metallic titanium, respectively. The solid lines in Fig. 6 are the computed velocity dispersions using the given Young's modulus. Young's modulus of porous AID-N film is estimated to be 370 $\mathrm{GPa}$, and is higher by $155 \mathrm{GPa}$ than that (215 GPa) of the ARE-N film. We examine the propriety of the estimated Young's modulus, by referring to published data. For instance, Ito et al. ${ }^{(10)}$ estimated polycrystalline TiN's modulus to be $470 \mathrm{GPa}$ using the Hill's isotropic elastic theory. They also measured the velocity dispersion using an ultrasonic spectra-microscope and found it to be $510 \mathrm{GPa}$ for $1.3^{-}$and $3.5^{-} \mu \mathrm{m}^{-}$ thick TiN films and $370 \mathrm{GPa}$ for $7.1-\mu \mathrm{m}$-thick TiN film. For residual stress measurement by $\mathrm{X}$-ray method, Young's modulus of $250 \mathrm{GPa}$ is often used ${ }^{(15)}$, however, this value appears to be smaller than the 
reported value $(370,510 \mathrm{GPa})$ by Ito et al. Young's modulus for ARE-N estimated by us is slightly smaller than that estimated by Ito et al. ${ }^{(10)}$, but is close to their data.

The higher modulus for the AID-N film, in spite of its poor film quality, is considered to be due to the extremely high compressive stresses, almost ultimate tensile strength $(3 \mathrm{GPa})$, induced by ion bombardment ${ }^{(3)}$. Although there are no experimental data showing the relationship between the Rayleigh wave velocity and residual stresses, Toda et al. ${ }^{(17)}$ reported that the $\mathrm{SH}$ wave velocity increases by about $50 \mathrm{~m} / \mathrm{s}$ with $1 \mathrm{GPa}$ compressive stress. If this relationship were to hold for the Rayleigh wave, the Rayleigh wave velocity would decrease by $150 \mathrm{~m} / \mathrm{s}$ with $3 \mathrm{GPa}$ compressive stress, leading to a higher Young's modulus. The elastic properties estimated from SAW velocity dispersion are significantly influenced by residual stresses in the film; however there seem to be no fundamental data to support this statement.

Furthermore, we examined the relationship between hardness and Young's modulus, since Tanaka et al. ${ }^{(18)}$ reported a linear relationship between them for $\mathrm{Si}_{3} \mathrm{~N}_{4}, \mathrm{SiC}$ and $\mathrm{Al}_{2} \mathrm{O}_{3}$ ceramics. Figure 7 shows the relationship between hardness and Young's modulus. Data are very close to the line given by Tanaka et al. $^{(18)}$

We also examined wave attenuation and film quality. Since the Rayleigh wave velocity of the TiN film is faster than that of the substrate metal, SAW becomes the leaky wave at frequencies higher than the cut-off frequency at which the Rayleigh wave velocity in the film exceeds the shear wave velocity of the substrate metal. The cut-off frequency for the TiN film was computed to be at around $90 \mathrm{MHz}$. However, we cannot detect the Rayleigh wave at frequencies higher than $65 \mathrm{MHz}$. The absence of a Rayleigh wave above $65 \mathrm{MHz}$ appears to be due to not the cut-off.frequency but wave attenuation in austenitic stainless steel. Stainless steel is known to be a

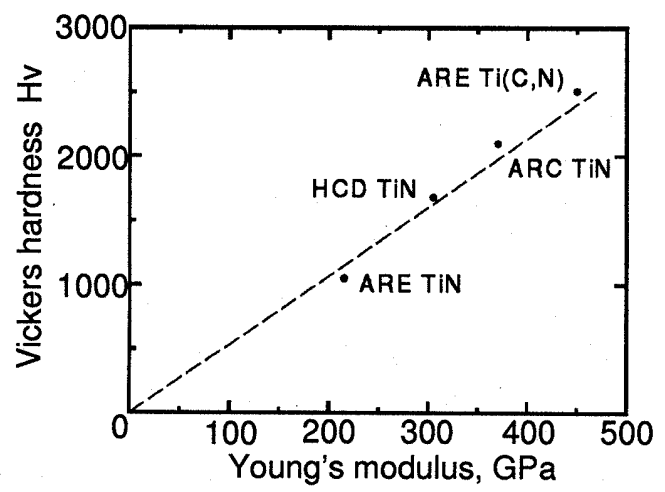

Fig. 7 Relationship between Vickers hardness and Young's modulus highly attenuative material ${ }^{(19)}$. Then we measured wave attenuation by changing both the frequency and SAW propagation distance. Figure 8 shows enveloped SAWs at $50 \mathrm{MHz}$ for the AID-N film (left) and those at $60 \mathrm{MHz}$ for SUS317J2 steel (right) as the propagation distance is changed from 0.54 to $0.63 \mathrm{~mm}$. No SAW could be observed at propagation distances longer than $0.63 \mathrm{~mm}$ for the AID-N film. In the case of the substrate metal, in addition to the larger attenuation, a second peak was observed at propagation distances of 0.59 and $0.63 \mathrm{~mm}$. The wavelength of SAW at frequency range from 50 to $60 \mathrm{MHz}$ is 45 to $50 \mu \mathrm{m}$ and is almost 10 times the thickness of TiN film. These wavelength of SAW is close to the large grain size of the substrate metal. Since the SAW propagates through both the surface TiN film and the substrate metal, the second peak observed in Fig. 8 ( b ) is considered to be due to the interference of grain boundary scattering. Wave scattering by average grain size $(20-30 \mu \mathrm{m})$ of the substrate metal becomes more pronounced at higher frequencies, finally resulting in no SAW.

Figure 9 shows the wave attenuation of films and substrate metal in the frequency range from 30 to 55 $\mathrm{MHz}$. The wave attenuation increases with increasing frequency in the power range of 3.6 to 4 . This frequency dependence agrees with that of Rayleigh
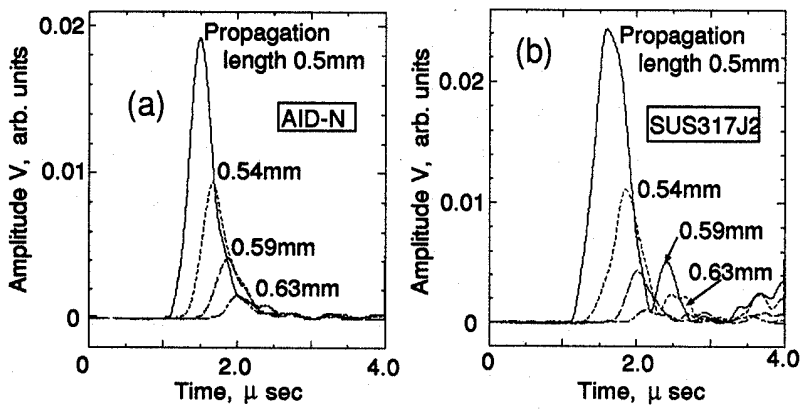

Fig. 8 Effect of propagation distance on the enveloped SAW at $50 \mathrm{MHz}$ for the AID-N film (a) and at 60 $\mathrm{MHz}$ for SUS317J2 (b)

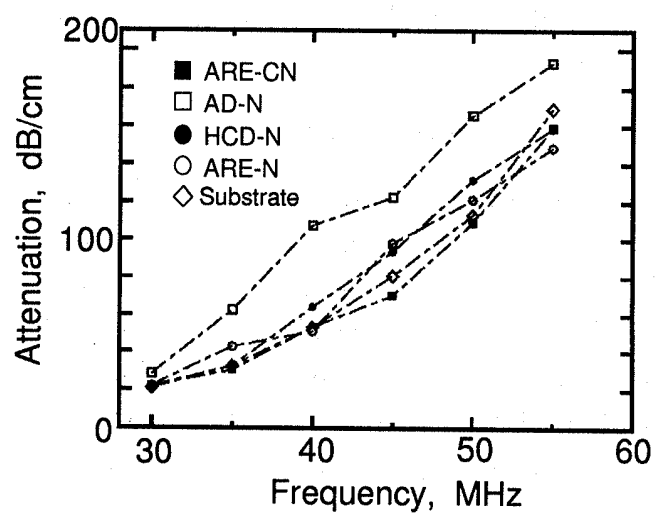

Fig. 9 Attenuation dispersion of the Rayleigh wave 
scattering. Higher attenuation of the AID-N film by almost 20 to $30 \mathrm{~dB}$ than that of the other films is due to the scattering by craters and splashed particles in the film. On the other hand, attenuation difference was hardly observed between HCD-N and ARE-N films. This implies that the quality of these two films cannot be diagnosed by wave attenuation.

\section{Conclusion}

We estimated the elastic constants of TiN films deposited by three vapor deposition methods from the velocity dispersion of laser SAW. Film quality was also estimated from wave attenuation in the frequency range from 30 to $60 \mathrm{MHz}$. The results are summarized below.

1) We developed a new laser SAW system (SIF system) in which the interference of two laser beams with different frequencies was scanned at the phase velocity of SAW. This system measures the phase velocity dispersion within $1 \%$ error as well as wave attenuation in the frequency range from 30 to 110 $\mathrm{MHz}$. This system also enables non-contact and nondestructive evaluation of materials without the need for a liquid couplant.

2) Young's moduli, estimated in such a way that the computed velocity dispersions agree with the measured ones, were found to be $370 \mathrm{GPa}$ for the AID-TiN film, $305 \mathrm{GPa}$ for the HCD-TiN film and $215 \mathrm{GPa}$ for the ARE-TiN film. A linear relationship between estimated Young's moduli and Vickers hardness was found for the TiN and $\mathrm{Ti}(\mathrm{C}, \mathrm{N})$ films.

3) No SAW was detected at frequencies higher than $65 \mathrm{MHz}$ for the $4.3-\mu \mathrm{m}$-thick TiN film deposited on SUS317J2 steel. This appears to be due to wave attenuation and scattering by grain boundaries in the substrate metal, and also by craters and splashed particles in the TiN film, rather than the cut-off frequency $(90 \mathrm{MHz})$ of the SAW. The wave attenuation of all TiN films increased from 3.6 to 4.0 power of the frequency ; however, the wave attenuation of the AID-N film with a number of pores and splashed particles is almost $20 \mathrm{~dB}$ higher than that of the other two TiN films.

\section{Acknowledgment}

We acknowledge the kindness of Dr. C. K. Jen, National Research Council of Canada, who supplied us with the SAW velocity calculation computer program. Part of this research was performed by the research fund from the Japan Science Foundation and Research Fellowships of the Japan Society for the Promotion of Science for Young Scientists.

\section{References}

(1) Fukai, T. and Matsumoto, K., Application of Ceramic Coatings to Instruments in Chemical Plant, Jour. of the Materials Science Society of Japan, (in Japanese), Vol. 31, No. 1 (1987), p. 4350.

(2) Ogawa, S., Fukai, T. and Takemoto, M., Strength and Fracture Mechanism of Vapor Deposition Films Estimated by the Analysis of Three Dimen sional Radiation Pattern of Elastic Wave, Zairyoto-kankyo (Corrosion Engineering), (in Japanese), Vol. 43, No. 12 (1994), p. 388-395.

(3) Ogawa, S., Fukai, T., Futatsugi, T. and Takemoto, M., Mechanical Properties and Internal Stress in the Vapor Deposited (Ti $(\mathrm{C}, \mathrm{N})$ ) Film Estimated by the Quantitative Analysis of $\mathrm{AE}$ Waves Emitted during the Loading, Jour. of the Surface Finishing Society of Japan, (in Japanese), Vol. 46, No. 5 (1995), p. 456-463

(4) Itou, M., Aizawa, T. and Kihara, J., Ultrasonic Microscopic Evaluation of PVD/CVD Coated Hard Materials, 44th Congress for Plastic Technology, (in Japanese), (1993), p. 115-118

(5) Ihara, I., Tokura, K., Aizawa, T., Furuguchi, H. and Kihara, J., Approach for Estimating Material Properties of Thin Film on Substrate by Inverse Analysis with Surface Wave Spectroscopy, Trans. Jpn. Soc. Mech. Eng., (in Japanese), Vol. 65, No. 579, A (1994), p. 2664-2671

(6) Cho, H. and Takemoto, M., Research of the Elastic Waves Generated by a Pulse Laser-Excitation Mechanism of Elastic Waves and Application to Nondestructive Testing, Jour. of the Materials Science Society of Japan, (in Japanese), Vol. 30, No. 4 (1994), p. 175-186.

( 7 ) Cho, H., Morikawa, Y. and Takemoto, M., Nondestructive Evaluation of Electroplated Layer Property Using the Velocity Dispersion of the Laser Induced Surface Acoustic Wave, Jour. of the Materials Science Society of Japan, (in Japanese), Vol. 30, No. 6 (1994), p. 304-312.

(8) Fukai, T. and Matsumoto, K., Electrochemical Evaluation of Pinhole in CVD, PVD Ceramic Coating, Zairyo-to-kankyo (Corrosion engineering), (in Japanese), Vol. 41, No. 11 (1994), p. 743740 .

(9) Mizuguchi, T., Yoshikawa, T. Tsuji, K. and Ko, E., Characterization of TiN, $\mathrm{ZrN}$ and $\mathrm{HfN}$ films deposited by AIP Process, Jour. of the Surface Finishing Society of Japan, (in Japanese)., Vol. 41, No. 5 (1990), p. 509-517.

(10) Ito, M., Aizawa, T. and Kihara, J., Nondestructive Quality Assurance of PVD/CVD Ceramic Coated WC/Co Cermets. The 44th meeting on Technology of Plasticity (in Japanese), (1993), p. 110-113

(11) Nishino, H., Tsukahara, Y., Nagata, T., Koda, T. and Yamanaka, K., Excitation of High Frequency Surface Acoustic Waves by Phase Velocity Scanning of a Laser Interference Fringe, Appl. Phys. 
Lett., Vol. 62 (1993), p. 2036-2039.

(12) Yamanaka, K., Kolosov, O.V., Nagata, Y., Koda, T., Nishino, H. and Tsukahara, T., Analysis of Excitation and Coherent Amplitude Enhancement of Surface Waves by the Phase Velocity Scanning Method, J. Appl. Phys., Vol.74, No. 11 (1993), p. 6511-6522.

(13) Adler, E.L., Jen, C.K., Farnell, G.K. and Slaboszewicz, J., Interactive Computer-Aided Analysis of Surface Acoustic Waves Using a Personal Computer, Proc. Ultrasonic International'85, King's College London, United Kingdom, (1985), p. 733736 .

(14) Japan Ceramic Society, Mechanical Properties of Ceramic, (1979), p. 123.

(15) Tabata, O. and Tsuchiya, T., Poisson's Ratio Evaluation of LPCVD Silicon Nitride Film, Trans. of the Institute of Electrical Engineers of Japan, Vol. 116-E, No. 1 (1996), p. 34-37
(16) Yamanaka, K., Study on Mechanical Property of Materials by Using Acoustic Microscopy, Jour. of Mechanical Engineering Laboratory, Vol. 141 (1987), p. 12

(17) Toda, H., Sakanaka, K. and Fukuoka, H., Proceedings of the Kansai branch meeting of the Japan Soc. of Mechanical Engineers, Vol. 67, No. 294-1, (1992), p. 10-12

(18) Tanaka, K. and Kishi, T., Nondestructive Evaluation of Materials in Relation to Micromechanics, Jour. of the Japan Institute of Metals, (in Japanese), Vol. 26, No. 1 (1987), p. 744-748.

(19) Hirose, S., Yamagachi, H., Yokono, Y. and Mizuma, K., Crystal Structure of Stainless Steel Casting and Their Ultrasonic Characteristics, Proc. of Symposium of Ultrasonic Testing, (in Japanese), (1995), p. 111-118

(20) Papadakis, E.P., Physical Acoustics, edited by W. P. Mason, Vol. IV part B, p. 269-326. 